MORAL SELF-CONCEPT AND PROSOCIAL BEHAVIOR

Running head: MORAL SELF-CONCEPT AND PROSOCIAL BEHAVIOR

The moral self-concept in preschool children: its dimensions and relation to prosocial behaviors

\title{
In Cognitive Development
}

Regina M. Sticker, Natalie Christner, Carolina Pletti, and Markus Paulus

Department Psychology, Ludwig-Maximilians-Universität München, Munich, Germany

Word count $=10.766$ (including abstract, tables, captions, references)

Acknowledgements: For help with data acquisition we are thankful to Milena Plach and Hanna Münch. This work was supported by a European Research Council Starting Grant [MORALSELF; No. 679000] to MP.

Correspondence concerning this article should be directed to

Regina M. Sticker, Department of Psychology,

Ludwig-Maximilians-Universität München, Leopoldstr. 13, 80802 Munich, Germany.

E-Mail: regina.sticker@psy.lmu.de 
MORAL SELF-CONCEPT AND PROSOCIAL BEHAVIOR

\section{The moral self-concept in preschool children: its dimensions and relation to prosocial behaviors}

Abstract. Recent theories have highlighted the relevance of the moral self-concept (MSC) for prosocial behavior. Its early development and internal structure is still unknown, though. With two studies, we aimed to investigate the structure of the MSC in early childhood. Furthermore, we explored prosocial behavioral correlates (helping, sharing, comforting). In a first study, we explored four to six-year-olds $(N=127)$. We assessed explicit (puppet-interview) and implicit (IAT) measures of the MSC and observed child behavior. Our results show that MSC was independent from other self-concept domains. The three prosocial dimensions (helping, sharing and comforting) appear to be represented within the MSC separately. While the IAT yielded no significant relations with behaviors, the explicit MSC was meaningfully related to prosocial behavior. The second study $(N=314)$ underscores the results of the first, by replicating the factor structure of the MSC in confirmatory factor analysis. In conclusion, the studies underscore the MSC's different dimensions and their relations to prosocial behaviors in preschool children.

Keywords: moral self-concept; prosocial behavior; early childhood 
MORAL SELF-CONCEPT AND PROSOCIAL BEHAVIOR

\section{The moral self-concept in preschool children: its dimensions and relation to prosocial behaviors}

\section{Introduction}

Moral behavior is an important aspect of everyday life (Hofmann, Wisneski, Brandt, \& Skitka, 2014). First signs of other-oriented concerns and behaviors emerge in the first years of life (for a review see Dunfield \& Kuhlmeier, 2013; Svetlova, Nichols, \& Brownell, 2010; Tomasello, 2019). Beyond acting prosocially, humans also reflect on themselves as moral creatures. They consider how important it is for them to be a moral person and to engage in moral behavior (Blasi, 1983). Being moral can thereby be perceived as being more or less central to one's self, and thus defines the extent of one's moral identity (Hardy \& Carlo, 2011). Empirical research with adults has demonstrated that moral identity relates positively to prosocial behavior (Aquino, Freeman, Reed, Lim, \& Felps, 2009; Hertz \& Krettenauer, 2016; Reynolds \& Ceranic, 2007). The development of a moral identity in adolescence is preceded by a moral self-concept (MSC) that is supposed to emerge in early childhood (Hardy \& Carlo, 2011). Notably, interventions aiming at the MSC in early childhood can increase prosocial or moral behavior (Bender, O'Connor, \& Evans, 2018; Bryan, Master, \& Walton, 2014). Yet, little is known on the early development of the MSC, its internal structure, and its relation to prosocial behavior during childhood (Hardy \& Carlo, 2011). In other words, do young children conceive themselves as moral agents and does their MSC actually relate to their prosocial behavior?

\subsection{The Ontogeny of a Moral Self}

The self-concept is a consistent representation of oneself (Jia, Lang, \& Schoppe-Sullivan, 2016). According to the hierarchical model of self-concept and self-perception theory (Bem, 


\section{MORAL SELF-CONCEPT AND PROSOCIAL BEHAVIOR}

1972; Shavelson, Hubner, \& Stanton, 1976), personal experiences are the basis of the selfconcept. In other words, these theoretical views suggest that children develop a self-concept based on their experiences with their own reactions and actions. This is supported by understanding that personality traits are stable over time and predict behavior, which develops between preschool and elementary school(Liu, Gelman, \& Wellman, 2007; Ruble, Newman, Rholes, \& Altshuler, 1988). Furthermore, around that age, children start to think about others in more abstract terms (Gnepp \& Chilamkurti, 1988; Rholes \& Ruble, 1984). Once that such an understanding has developed, the urge to act consistently with one's self becomes more salient (Blasi, 1983). Thus, self-concept and behavior appear to affect each other. Self-concept research supports this relation between children's behavior and their self-concept for the academic, social, and physical self-concept (middle school students, Knowles, Niven, Fawkner, \& Henretty, 2009; high school students, Marsh, Hau, \& Kong, 2002; second to eighth grade students, Salley, Vannatta, Gerhardt, \& Noll, 2010). With age, the self-concept becomes more differentiated, adding more domains and subdomains (henceforth called dimensions), which differ in evaluations (Marsh, 1990). Moreover, the information condenses and forms an abstract, global representation of the self (here four- to seven-year-olds, Cimpian, Hammond, Mazza, \& Corry, 2017). This development could be supported by children's increasing ability for internal reflection around the age of four years (Allen \& Bickhard, 2018). A positivity bias usually underlies the self-concept in Kindergarten age. That is, children tend to think of themselves in overly positive terms. For example, they tend to say they are excellent in everything they do and overestimate their abilities (Harter, 2015; Mezulis, Abramson, Hyde, \& Hankin, 2004). With increasing age, the self-concept is increasingly in line with external criteria (such as grades; Marsh \& Martin, 2011).

Developmental theories and empirical research has suggested that the self-concepts of physical ability and verbal ability fall in two different self-concept domains (Marsh, Ellis, \& 


\section{MORAL SELF-CONCEPT AND PROSOCIAL BEHAVIOR}

Craven, 2002). That means, that the self-concept consists of different independent domains, as suggested by the hierarchical model of self-concept (Brunner et al., 2010). Most important for our study, influential developmental theories propose the existence of a MSC(for a review see Hardy \& Carlo, 2011) and that its early roots are in early childhood (Krettenauer, 2013). The MSC is defined as "children`s self-representations about their moral behavioral preferences" (Sengsavang \& Krettenauer, 2015, p. 214). Based on these considerations, we assume that it is distinct from the other self-concept domains, just as they are distinct from each other.

Early indicators of the MSC, such as showing signs of guilt and shame, emerge around the third and fourth year of life (Kochanska, Koenig, Barry, Kim, \& Yoon, 2010; Vaish, Carpenter, \& Tomasello, 2016). At that age, it has been suggested that the MSC consists of internalized parental rules, norms, and personal experience as good or bad agents (Kochanska, 2002). Rules, norms, and experiences are proposed to not yet be combined to a meaningful self at four years, but to rather exist next to each other (Kochanska, 2002). First evidence of the early meaning of the MSC comes from a study by Kochanska (2002). She observed children (longitudinally from 14 to 56 months) and their mothers in different situations. At the 56-months measurement point, children responded to questions about their moral self using a puppet-interview, for example concerning their empathy: "If I see a child being hurt, I try to help.” vs. “..., I don't try to help". Results show that previous eager compliance at 14 to 45 months correlated with children's moral selves, at least in boys. Around 5 to 6 years children`s MSC is supposed to become internally consistent (i.e., similar statements within the moral domain; Kochanska et al., 2010). Krettenauer and colleagues (2013) administered a puppet-interview to five to twelve-year-olds about their moral self-concepts. Results reveal two differentiated and internally consistent scales: preference for prosocial behavior and aversion of antisocial behavior (Krettenauer, Campbell, \& Hertz, 2013). These findings suggest that early to middle childhood is a central phase for the initial emergence of a MSC. Therefore, we decided to focus in our study on this 


\section{MORAL SELF-CONCEPT AND PROSOCIAL BEHAVIOR}

age group. Further on, we focused on the preference for prosocial behavior as representative of MSC (similar to Aquino \& Reed, 2002, who created the well established Moral Identity

Questionnaire for adults). This choice for investigating the self-concept regarding concrete, observable behaviors in the moral domain rather than abstract moral concepts was for a reason: Children have a hard time expressing abstract concepts or applying them to themselves (Harter, 2015). In other words: children rather act than explain. This is why breaking down complex reasoning to concrete behavioral indicators is the status quo for research with young children (here for example four to five-year-olds, Marsh, Ellis, et al., 2002; and five- to seven-year-olds, Measelle, John, Ablow, Cowan, \& Cowan, 2005).

Thus far, little is known on whether the MSC forms an independent self-concept domain that differs from other aspects of the self. Based on self-perception theory (Bem, 1972) and the hierarchical model of self-concept(Shavelson et al., 1976), there are reasons to assume that the MSC of children is distinct from other self-concept domains. While previous studies examined the presence of a moral self in early childhood(Kochanska, 2002; Krettenauer et al., 2013); they did not include self-concept measures for other domains. Hence, it is an open question whether the MSC is distinct from other self-concept domains. The current study aimed to contribute to this question.

\subsection{Moral Self-Concept and Prosocial Behavior}

Prosocial behavior is defined as behavior that benefits someone else(Eisenberg, Fabes, \& Spinrad, 2006). Recent work suggests that prosocial behavior can be classified into three different domains, namely instrumental need (leading to helping), emotional distress (leading to comforting), and material desire (leading to sharing; Dunfield, 2014; Paulus, 2018). These three prosocial dimensions were found not to correlate, to emerge at different times in 


\section{MORAL SELF-CONCEPT AND PROSOCIAL BEHAVIOR}

development and to different extents within one child (Dunfield \& Kuhlmeier, 2013). The reviewed theoretical considerations on the development of self-concept could indicate that the MSC in preschool children relates to their prosocial behavior. Different researchers proposed that early prosocial behavior consists of three distinct dimensions (Dunfield, 2014; Dunfield, Kuhlmeier, O’Connell, \& Kelley, 2011; Paulus, 2018).We hypothesized that the MSC should consist of the same three dimensions as prosocial behavior: a self-concept for helping, sharing, and comforting. Furthermore, as the MSC can be supposed to develop based on perceptions of one's own behavior, we hypothesized that the three distinct behavioral dimensions will meaningfully relate to the three distinct self-concept dimensions.

Besides an explicit self-concept, recent research suggested the existence of an implicit selfconcept in adults (De Cuyper et al., 2017; Peters \& Gawronski, 2011). The co-existence of an implicit and an explicit self-concept is captured in so-called dual process models(Gerstenberg, Imhoff, Banse, \& Schmitt, 2014; Strack \& Deutsch, 2004).These models suggest that the explicit self-concept represents active thoughts and evaluations(Aquino \& Reed, 2002) whereas the implicit self-concept represents learned associations between the self and other concepts, such as morality (Perugini \& Leone, 2009). To our knowledge, the relation between the implicit MSC and prosocial behavior has not been investigated in young children. The implicit selfconcept is particularly interesting in research with children. Young children's verbal abilities are limited. An implicit test could capture a facet of children`s self-concept, that is not explicitly accessible to the children themselves (here four-year-olds, Cvencek, Greenwald, \& Meltzoff, 2011). Hence, we want to investigate the relation between the implicit MSC of preschool children and prosocial behavior.

\subsection{The present Studies}




\section{MORAL SELF-CONCEPT AND PROSOCIAL BEHAVIOR}

The current study aims at exploring the early origins of the MSC with respect to different prosocial behaviors and in relation to other domains of the self-concept. We chose to focus on the positive, prosocial aspects of morality, rather than the avoidance of antisocial behavior. This was due to different considerations: first, we aim to increase comparability with a long tradition of research on moral identity in adults in which moral identity was assessed as concordance with a number of positive moral traits (Aquino et al., 2009; Aquino \& Reed, 2002; Jennings, Mitchell, \& Hannah, 2015). Second, we aim to explain active, prosocial behavior. In other words, we focus on the active, prosocial part of the MSC. Thus, when trying to explain prosocial behavior, it is conceptually appropriate to focus on the prosocial aspects of the MSC. Third, in the specific case of MSC, preference for prosocial behavior appears to be more independent of social desirability than avoidance of antisocial behavior (Krettenauer et al., 2013). This is particularly important, as we aim to investigate the relation of MSC and observable behavior.

In order to investigate the early ontogeny of the MSC, we explored its structure and function in early childhood with two studies. In study1, we examined four hypotheses: According to the multifaceted hierarchical model, the self-concept is structured in different domains (Brunner et al., 2010; Shavelson et al., 1976). Thus, we hypothesized that the MSC is distinct from other self-concept domains (H1). To test this hypothesis, we decided to use conceptually different domains as comparisons (verbal and physical self-concept) as we had a clear hypothesis about them. We conducted an exploratory factor analysis with the items of the explicit MSC interview. If we are able to find distinct factors (moral, verbal, physical self-concept) in our data, we can conclude that the prosocial dimensions exist independently of other self-concept domains at all.

According to self-perception theory (Bem, 1972), self-concept dimensions derive from concrete behaviors - helping, sharing, and comforting. These behaviors appear to shape distinct dimensions in early childhood (Dunfield \& Kuhlmeier, 2013). Hence, we hypothesized that the 


\section{MORAL SELF-CONCEPT AND PROSOCIAL BEHAVIOR}

MSC divides in the same dimensions: helping, sharing, and comforting (H2). Following theories on relations between behavior and self-concept, we hypothesized that the self-concept dimensions correlate with the corresponding prosocial behaviors (H3). According to the dual process model, the implicit self-concept offers information on top of the explicit in particular due to active verbal skills, because it seems less dependent on active verbal skills. Thus, we hypothesized, that the implicit MSC relates to prosocial behaviors (H4). In study 2, we aimed at further confirming the existence of three distinct dimensions of the MSC (H2) by means of a confirmatory factor analysis in a large sample.

To test these hypotheses, we assessed preschool children's explicit and implicit MSC, and their prosocial behaviors (helping, sharing, comforting). To measure the explicit self-concept, we relied on a puppet-interview approach (e.g., Measelle, Ablow, Cowan, \& Cowan, 1998), that we adapted from an interview by Krettenauer et al. (2013). In order to assess children's prosocial behavior, we adapted established tasks to assess preschool children's helping, sharing, and comforting (Dunfield \& Kuhlmeier, 2013; Kenward, Hellmer, Winter, \& Eriksson, 2015; Svetlova et al., 2010). To assess the implicit self-concept, we adapted an Implicit Association Test (IAT; Perugini \& Leone, 2009) measuring attitudes (Good, Bad) towards Self or Other. We analyzed the reaction latency in the different conditions of the IAT in relation to the prosocial behaviors.

\section{Study 1}

\subsection{Method}

\subsubsection{Participants}

The final sample consisted of 127 four- to six-year-olds (62 female; $M=64.77$ months, $S D$ $=9.86)$. There was no age difference between genders, $t(125)=.88, p=.513$. Eight additional children were excluded because of not completing the study due to language problems $(n=2)$ 


\section{MORAL SELF-CONCEPT AND PROSOCIAL BEHAVIOR}

and fussiness $(n=6)$. Sample size is based on previous work which examined differentiation of preschool children's self-concept (Marsh, Ellis, et al., 2002). Moreover, according to a power analysis a sample of 109 participants would suffice to detect a small effect $\left(f^{2}=0.15\right)$ with a power of $80 \%$ and alpha of .05 when calculating a linear multiple regression with eight predictors. We kept testing until we had a comparable number of children of each age. We recruited families via mail. Their addresses came from the city's natal register. A third of parents raised their children bilingually, $61 \%$ held a university's degree, and $14 \%$ completed high school. The sample consisted of 105 Western European, 10 Eastern European, 8 Middle Eastern, 3 Asian and 2 African children. The children's caregivers gave written informed consent for participation. The local ethics committee approved the study. Parents received compensation for travel expenses. Each child received a small gift and stickers.

\subsubsection{Procedure}

Testings took place at the developmental laboratory at \#\#blinded for purpose of review\#\#. Each child was tested individually in a quiet room by a female experimenter. We videotaped the experimental session for later coding. At first, the children performed the sharing task, then the puppet-interview, then the helping task. After that, the children completed the IAT. Subsequently, they performed the comforting task.

\subsubsection{Measures}

The tasks relied on established measures comprising behavioral tasks (sharing, helping, comforting) and self-concept measures (puppet-interview, IAT). This study is the first measurement point of an ongoing longitudinal study and we report here only the measures relevant for this study. We did not counterbalance the measures to keep order effects constant across participants, allowing to investigate individual differences. 


\section{MORAL SELF-CONCEPT AND PROSOCIAL BEHAVIOR}

2.1.3.1 Behavioral tasks. Sharing. This task was based on Smith, Blake, and Harris (2013), who conducted their study with three- to eight-year-olds. Children could decide how many out of 4stickers they wanted to share with an absent child. The instructions were: "Here are 4 stickers. They are yours now. You can share them with another child. [Experimenter places picture of other androgynous child] This is Nina/Nico [depending on gender of participant]. You can give the Nina/Nico one, two, three, four or no sticker. You can decide by yourself. The stickers for Nina/Nico come in this box. When you are done, close the box." Signaling the end of the transaction by closing the box reduced the demand characteristic of having to share. The number of items in the box (0-4 items) represents children's sharing behavior.

Helping. Following previous studies with preschoolers, we used a costly helping task (Svetlova et al., 2010). Experimenter and child played a competitive game, in which the child was asked to finish a jigsaw puzzle and the experimenter had to draw the depiction of the puzzle. During this game, the experimenter dropped items (ten pens). This gave the child simultaneously an advantage to win or an opportunity to help. Prompts were "Oh" (seven seconds pause), "Now I can't keep on drawing” (seven seconds pause), “Ok, then I will quickly pick up the pens". If the child helped at any point, no further prompts followed. If the child did not help, the experimenter picked up the pens after the last prompt. Then the game continued, ending with the child winning the game. We decided to use a competition scenario, because helping someone while making personal sacrifice is more clearly a prosocial act (Gneezy, Imas, Brown, Nelson, \& Norton, 2012). Child behavior was coded from the video recordings of the task and scored on a 4-point scale, $0=$ no reaction; $1=$ short help (e.g., "You have to pick them up"); 2 = moderate help (picking up a few pens, or only helping after the second prompt); $3=$ intensive, immediate help (picking up all the pens, right away). The helping coding scheme is adapted from Vaish, Carpenter, and Tomasello (2009)and Newton, Goodman, and Thompson (2014).To ensure interrater reliability, a trained assistant coded one third of the behaviors in 


\section{MORAL SELF-CONCEPT AND PROSOCIAL BEHAVIOR}

addition to the first coder. We achieved a high reliability for the behavioral helping task. The Intra-Class Correlation (ICC) was .95 with a 95\% CI [.90 to .98], $F(26,26)=39.41, p<.001$.

Comforting. The procedure was adapted from Young, Fox, and Zahn-Waxler (1999). The experimenter pretended to hit her foot. This was followed by "Ow" and a distressed facial expression, rubbing the foot, whining, (seven seconds pause); "I bumped my foot!" (seven seconds pause). If the child comforted, no further prompts followed. If the child did not comfort, the experimenter reduced her hurt facial expressions after the last pause and said, "Ah, I am better now." She continued with explaining the next game. To code comforting behavior, we followed previous work and relied on the global empathy scale (i.e., a combined scale comprising empathic concern and prosocial behavior). We used a global score, because this score includes the variety of comforting tendencies and behavior (Robinson, Zahn-Waxler, \& Emde, 1994). Child behavior was scored from the video recordings on a seven point scale: $0=$ not involved at all (e.g., casually investigating a toy); 2 = slight concern (e.g., tension in upper body and face), no prosocial behavior; 4 = moderate concern (e.g., change in facial expression from slight smile to raised eyebrows and open mouth), slight prosocial behavior (e.g., "Yes, this hurts."); 6 = strong concern (e.g., very worried face), prosocial behavior (e.g., singing a healing song).Ratings between the scores were possible, if a behavior fell in between two anchor points. The reliability for the behavioral comforting task was high. The ICC was .74 with $95 \%$ CIs $[.51$ to .87$], F(26,26)=6.61, p<.001$.

\subsubsection{Self-concept measures. Puppet-Interview. The puppet-interview is an established} measure to assess children's self-concept (Measelle et al., 1998). Our interview items were based onKrettenauer et al. (2013) and Marsh, Ellis, et al. (2002). We addressed the prosocial dimensions of helping, sharing, and comforting, as well as physical and verbal abilities. Each dimension consisted of four items with the exception of physical (five items), resulting in 21 items. The prosocial items are adaptations from Krettenauer et al. (2013). The physical and 


\section{MORAL SELF-CONCEPT AND PROSOCIAL BEHAVIOR}

verbal items are adaptation from Marsh, Ellis, et al. (2002). We rephrased the questions to statements in order to fit the interview format. Additionally, we adapted some items to fit our preschool sample better (see Table 2 for the final items). For each item, two puppets stated opposing information (e.g., "I like to help doing the dishes" vs. "I don't like to help doing the dishes"). The opposing puppets for each item were identical. By this, we ensured that children replied based on the statements rather than the puppets' appearances. In order to reduce carry over effects, we exchanged the puppets after each item pair. After each item pair, the experimenter asked: “And you? Are you more like this puppet or like this puppet?" The child chose the puppet with whom they identified most. Next, the experimenter asked: "Are you a bit or a lot like this puppet?" If the child could not side for one or the other puppet, the experimenter asked: "Are you sometimes like this one and sometimes like that one? So, in the middle?" This resulted in a five-point Likert-scale for each item: $1=$ a lot like the negating puppet; $2=\mathrm{a}$ bit like the negating puppet; $3=$ not like either of the puppets or equal identification; $4=$ a bit like the affirmative puppet; $5=$ a lot like the affirmative puppet.

We used the same method to include a control measure of social desirability. Social desirability does not represent a part of the self-concept, but functions as control measure to test whether the MSC explains variance in behavior beyond a social desirable response. We administered three social desirability items by Krettenauer et al. (2013), "When I get what I asked for I always say thank you", "I'm never angry", and "I always say please, if I want to have something".

Implicit self-concept measure. The implicit association test (IAT) is a computer-based test in which participants sort words in two different dimensions by clicking one of two designated buttons as fast as possible (see Greenwald, McGhee, \& Schwartz, 1998). We used the moral self-concept IAT by Christner, Pletti and Paulus (2020). This task was based on an IAT for preschoolers, which has been successfully used with four-year-olds (Cvencek et al., 2011). The 


\section{MORAL SELF-CONCEPT AND PROSOCIAL BEHAVIOR}

first dimension included the categories Self and Others (I, me, mine vs. other, they, their).The second dimension reflected the categories of Good and Bad attributes of pro- and antisocial behaviors (to help, to share, to comfort vs. to hit, to steal, to push). In congruent trials, items of the categories Self and Good were paired on one side of the screen and one button. The category Other and Bad were paired on the other side of the screen. In incongruent trials, the target categories Self and Bad were paired on one side of the screen and the category Other and Good on the other side. As many of the children were not literate yet, we presented the items in audio. First, the experimenter checked that the children knew all the words and were able to sort them to the correct sides of the dimensions. The instructions for the children were: "Every time you hear 'I', 'me' or 'mine' you push this button" (pointing at the designated button for this trial). "Every time you hear 'other', 'they' or 'their' you press this button" (pointing at the other designated button). This was followed by the question: "So if you hear 'I', which button do you press?" The experimenter corrected if the response was wrong or continued with a new item. The same procedure was executed for the pro- and antisocial behaviors. Thereafter, the task started.

The entire task consisted of seven blocks: Good vs. Bad discrimination (12 trials, learning block), Self vs. Other discrimination (12 trials, learning block), two paired blocks (24 trials each), Good vs. Bad discrimination with reversed sides (24 trials, learning block), two reversed paired blocks (24 trials). The experimenter introduced each new block. Here is an example of the congruent paired block: "Every time you hear 'I', 'me', 'mine' or 'to help', 'to share', 'to comfort' you press this button. Every time you hear 'other', 'they', 'their' or 'to hit', 'to steal', ‘to push', you press this button. Ok?” The explanation was accompanied by according pointing gestures. A fixation cross appeared for $400 \mathrm{~ms}$ between trials. If the children made a mistake, a red question mark appeared on screen. The task continued as soon as the child responded correctly. 


\section{MORAL SELF-CONCEPT AND PROSOCIAL BEHAVIOR}

We measured the average response latency for those children whose accuracy was significantly higher than chance $(n=102)$ based on the scoring algorithm by Greenwald, Nosek, and Banaji (2003). We calculated a difference score between the incongruent and congruent condition. The difference score reflects the association between Self and Good vs. Bad attributes. The higher the score, the stronger the association between self and prosocial attributes. In our sample, we found a split-half reliability of .70.

\subsection{Results}

We first describe the results concerning the internal structure of the MSC (H1 and H2). Second, we investigate the relation of the MSC (explicit and implicit) and prosocial behavior (H3 and H4). For descriptive purposes, a zero-order correlation matrix of all variables is presented in Table 1. 
Table 1

Correlations of all scales

\begin{tabular}{|c|c|c|c|c|c|c|c|c|c|c|}
\hline & \multicolumn{3}{|c|}{ Behavioral } & \multicolumn{6}{|c|}{ Explicit } & \multirow{2}{*}{$\begin{array}{c}\text { Implicit } \\
10\end{array}$} \\
\hline & 1 & 2 & 3 & 4 & 5 & 6 & 7 & 8 & 9 & \\
\hline \multicolumn{11}{|l|}{ Behavior } \\
\hline 1. Share & -- & & & & & & & & & \\
\hline 2. Help & .15 & -- & & & & & & & & \\
\hline 3. Comfort & .17 & $.24 * *$ & -- & & & & & & & \\
\hline \multicolumn{11}{|l|}{ Self-Concept } \\
\hline 4. Share & $.24^{* *}$ & -.08 & .09 & -- & & & & & & \\
\hline 5. Help & -.09 & .01 & .03 & $.22 *$ & -- & & & & & \\
\hline 6. Comfort & $.31 * *$ & .10 & $.20^{*}$ & .16 & $.22 *$ & -- & & & & \\
\hline 7. Physical & -.02 & -.06 & -.04 & $.20^{*}$ & .14 & .06 & -- & & & \\
\hline 8. Verbal & .08 & .01 & .16 & $.23^{*}$ & .11 & .13 & $.19^{*}$ & -- & & \\
\hline 9. Social Desirability & .11 & .05 & .08 & .08 & $.35^{* *}$ & .18 & .14 & -.03 & -- & \\
\hline \multicolumn{11}{|l|}{ IAT } \\
\hline 10. Difference Score & -.11 & .07 & .06 & .00 & -.09 & .04 & .02 & $.37^{* *}$ & -.04 & -- \\
\hline 11. Age & .09 & .03 & $.22 *$ & .18 & .18 & -.16 & -.04 & $.26^{* *}$ & $-.21 *$ & $.20^{*}$ \\
\hline
\end{tabular}

Note. The columns are the transposed rows. Scales 4-9 constitute the puppet-interview.

$* p<.05 ; * * p<.01$ 
Means and standard deviations of the prosocial behavioral dimension and explicit MSC measures are displayed in Table 2. Note that we assessed the physical and the verbal SC, but not corresponding behavioral abilities.

Table 2

Descriptive Information on the Behavioral and Self-Concept Measures

\begin{tabular}{lcccc} 
& \multicolumn{2}{c}{ Behavior } & \multicolumn{2}{c}{ Self-Concept } \\
& & & \multicolumn{2}{c}{ Puppet-Interview } \\
Dimension & $n$ & $M(S D)$ & $n$ & $M(S D)$ \\
\hline Share & 127 & $0.85(1.04)$ & 121 & $4.05(0.89)$ \\
Help & 123 & $1.20(1.28)$ & 125 & $3.57(1.15)$ \\
Comfort & 126 & $2.07(1.23)$ & 120 & $3.31(1.19)$ \\
Physical & & & 120 & $3.93(0.75)$ \\
Verbal & & & 122 & $4.28(0.69)$ \\
Social Desirability & & & 123 & $3.44(1.11)$ \\
\hline
\end{tabular}

Note. The range for sharing behavior was $0-4$, for helping behavior 0 3 , and for comforting behavior 0-6. For the self-concept measures, the range was 1-5, excluding items $\mathrm{Sh} 2, \mathrm{He} 1$ and $\mathrm{Co} 1$ due to subsequent results from factor analysis.

\subsubsection{The self-concept is differentiated.}

We analyzed the factor structure of the puppet-interview (H1). We conducted an exploratory factor analysis (EFA) with varimax rotation. When creating a new questionnaire, an exploratory factors analysis can help identifying outlying items and fitting items. This method ensures that only the most appropriate items get carried to the latest version of the questionnaire (see Aquino $\&$ Reed, 2002). The varimax rotation maximizes the differences between factors, as we do not expect the three factors to relate with each other (Field, 2015). As we employed items from 


\section{MORAL SELF-CONCEPT AND PROSOCIAL BEHAVIOR}

established interviews and created new items, the first step is an EFA to ensure that our new interview matches the general expected structure.

We investigated the three main factors of the puppet-interview: prosocial, verbal and physical. We excluded three items (Co1, Ve4, Ph1) from further analysis due to low correlations with the other items(based on the "garbage in, garbage out" problem; Field, 2015, p. 685). In the exploratory factor analysis, the Kaiser-Meyer-Olkin (KMO) - without the excluded items - was .60, being above the acceptable limit of .50 (Field, 2015). Overall, our analyses showed a three-factor solution. The three factors explained a variance of $37.15 \%$. Table 3 displays the factor loadings and internal consistency after rotation. The items that loaded on the same factor suggest that factor one stands for prosocial behavior, factor two for verbal abilities, and factor three for physical abilities.

Table 3

Factor Loadings for Principal Component Factor Analysis with Varimax Rotation of the Puppet-Interview

\begin{tabular}{llccc}
\hline Code & Item-Content & Prosocial & Verbal & Physical \\
\hline Sh1 & I like to share my pencils. & .29 & .35 & .11 \\
Sh2 & I like to share my toys with other children. & .54 & .11 & .09 \\
Sh3 & I take care that everyone gets the same amount. & .16 & .34 & .25 \\
Sh4 & I like to let other children play with my toys. & $\mathbf{. 5 0}$ & .01 & .09 \\
Co2 & I like to comfort a child, even if it was mean to me once. & $\mathbf{. 4 6}$ & -.11 & .15 \\
Co3 & I stop playing my favorite game to comfort a crying child. & $\mathbf{. 4 8}$ & .20 & -.20 \\
Co4 & I comfort a child, even when it has started the fight itself. & $\mathbf{. 5 9}$ & -.01 & .11 \\
He1 & I like to help tidy up the play area. & $\mathbf{. 7 1}$ & .24 & .18 \\
He2 & I like to help folding the laundry. & $\mathbf{. 5 4}$ & .09 & -.25 \\
He3 & I like to help setting the table at home. & $\mathbf{. 5 8}$ & .11 & -.18 \\
He4 & I like to help doing the dishes. & $\mathbf{. 5 9}$ & .01 & .24
\end{tabular}




\begin{tabular}{|c|c|c|c|c|}
\hline $\mathrm{Ph} 2$ & I would like to be strong. & .05 & .07 & .53 \\
\hline $\mathrm{Ph} 3$ & I can run very fast. & .07 & -.02 & .60 \\
\hline $\mathrm{Ph} 4$ & I can jump very far. & .08 & -.06 & .71 \\
\hline Ph5 & I like to romp around. & -.02 & .44 & .45 \\
\hline Ve1 & I enjoy looking at books. & .13 & .59 & -.23 \\
\hline $\mathrm{Ve} 2$ & I enjoy listening to stories. & .07 & .70 & .04 \\
\hline Ve3 & I like it when people read me a story. & -.09 & .76 & -.01 \\
\hline \multicolumn{2}{|c|}{ Eigenvalue } & 2.71 & 1.91 & 1.75 \\
\hline \multicolumn{2}{|c|}{$\%$ of variance } & 15.96 & 11.71 & 10.30 \\
\hline \multicolumn{2}{|c|}{ Cronbach's $\alpha$} & .72 & .52 & .46 \\
\hline
\end{tabular}

Note. Factor loadings $>.40$ appear bold. $\mathrm{Sh}=$ Sharing, $\mathrm{Co}=$ Comforting, $\mathrm{He}=\mathrm{Helping}, \mathrm{Ph}=$ Physical, Ve $=$ Verbal. Cronbach's $\alpha$ as measure of internal consistency for items $>.40$ on that factor. Items were translated from German.

\subsubsection{The MSC is threefold.}

In a next step, we investigated the internal structure of the eleven items of the prosocial factor (H2). We assumed three dimensions within this factor: helping, comforting, sharing. We conducted an EFA with oblique rotation, because it allows the factors to correlate with each other(Field, 2015). Based on the previous analysis we found out that the prosocial domains are related. The KMO measure for the analysis was .73 , which is above the acceptable limit of .50 (Field, 2015). The three expected factors all had Eigenvalues higher than one and explained a total amount of $52.25 \%$ of the variance. The factors clustered in the three expected dimensions helping, comforting and sharing as Table 4depicts. The only exception was one sharing item ("I like to share my toys with other children.") that fit into the helping dimension. We excluded this item from subsequent analyses. We only included items in further analysis if the following 
criteria were met (Stevens, 2012): first, items loaded on one factor $(>.40)$ and not on others $(<.40)$; second, the content of the items was conceptually coherent with the factor.

Table 4

Factor Loadings for Principal Component Factor

Analysis with Direct Oblimin Rotation of the Puppet

Interview's Prosocial Items

\begin{tabular}{|c|c|c|c|}
\hline Code & Helping & Comforting & Sharing \\
\hline Sh1 & -.21 & .16 & .76 \\
\hline $\mathrm{Sh} 2$ & .40 & .16 & .26 \\
\hline $\operatorname{Sh} 3$ & .08 & -.12 & .52 \\
\hline Sh4 & .11 & .00 & .71 \\
\hline $\mathrm{Co} 2$ & -.24 & .85 & .07 \\
\hline Co3 & .10 & .64 & -.03 \\
\hline $\mathrm{Co} 4$ & .16 & .70 & -.04 \\
\hline $\mathrm{He} 1$ & .39 & .39 & .34 \\
\hline $\mathrm{He} 2$ & .68 & -.16 & .18 \\
\hline $\mathrm{He} 3$ & .76 & -.03 & -.02 \\
\hline $\mathrm{He} 4$ & .73 & .20 & -.20 \\
\hline Eigenvalue & 2.37 & 2.16 & 1.89 \\
\hline Cronbach's $\alpha$ & .67 & .62 & .50 \\
\hline
\end{tabular}




\section{MORAL SELF-CONCEPT AND PROSOCIAL BEHAVIOR}

Note. Factor loadings $>.40$ appear bold. Cronbach's $\alpha$ as measure of internal consistency for items $>.40$ on that factor.

\subsubsection{The MSC corresponds to prosocial behavior.}

We investigated the relation of the explicit MSC and prosocial behavior (H3). In three stepwise linear regressions, we used helping, sharing and comforting behavior as dependent variables and the explicit self-concept measures as predictors (i.e., sharing, helping, comforting, verbal, and physical of the puppet-interview). We averaged the items for each scale that the previous factor analysis revealed. The assumptions for regressions were met, with the exception of sharing behavior, which needed to be weighted due to heteroscedasticity. In a first step, before inserting the mentioned predictors, we included age and social desirability as an obligatory predictor, because higher age relates to increased prosocial behavior (Smith et al., 2013; Taylor, Eisenberg, Spinrad, Eggum, \& Sulik, 2013). Results of the stepwise regressions are presented in Table 5.

The regression for the dependent measure sharing behavior showed an effect of the comforting and sharing MSC, $F(3,106)=17.29, p<.001$. Age did not contribute to the regression of sharing behavior. None of the other predictors became significant. The regression for the dependent measure comforting behavior indicated an effect of the comforting MSC and age, $F(2,112)=5.57, p=.005$. None of the other predictors became significant. The regression for the dependent measure helping behavior was non-significant, $F(1,113)=0.04, p=.841$.

\section{Table 5}

Linear Regression of explicit and implicit MSC and Prosocial Behavior.

Behavior 
MORAL SELF-CONCEPT AND PROSOCIAL BEHAVIOR

\begin{tabular}{|c|c|c|c|c|c|c|c|c|c|}
\hline Predictor & $\beta$ & $95 \% \mathrm{CI}$ & $\mathrm{t}$ & $\beta$ & $95 \% \mathrm{CI}$ & $\mathrm{t}$ & $\beta$ & $95 \% \mathrm{CI}$ & $\mathrm{t}$ \\
\hline \multicolumn{10}{|c|}{ Explicit Regression } \\
\hline Age & .11 & {$[-0.01,0.02]$} & 1.24 & $.24^{*}$ & {$[0.01,0.05]$} & 2.64 & -.01 & {$[-0.03,0.02]$} & -0.09 \\
\hline SoDe & -.05 & {$[-0.17,0.09]$} & -0.60 & .10 & {$[-0.10,0,31]$} & 1.01 & .05 & {$[-0.16,0.28]$} & 0.51 \\
\hline \multicolumn{10}{|l|}{$\underline{\mathrm{SC}}$} \\
\hline Comfort & $.28 * *$ & {$[0.08,0.32]$} & 3.23 & $.20^{*}$ & {$[0.01,0.40]$} & 2.13 & n.s. & & \\
\hline Share & $.38 * *$ & {$[0.11,0.31]$} & 4.17 & n.s. & & & & & \\
\hline Help & $\mathrm{n} . \mathrm{s}$ & & & & & & & & \\
\hline Physical & n.s. & & & & & & & & \\
\hline Verbal & n.s. & & & & & & & & \\
\hline $\mathrm{R}^{2}$ & & $.31 * *$ & & & $.07 *$ & & & -.01 & \\
\hline \multicolumn{10}{|c|}{ Implicit Regression } \\
\hline Age & .13 & {$[-0.01, .0 .04]$} & 1.36 & $.22 * *$ & {$[0.01,0.06]$} & 2.33 & -.11 & {$[-0.04,0.01]$} & -1.09 \\
\hline IAT & n.s. & & & & & & & & \\
\hline$\Delta \mathrm{R}^{2}$ & & .01 & & & .04 & & & .00 & \\
\hline
\end{tabular}

Note. $\mathrm{CI}=$ confidence interval. $\mathrm{SC}=$ Self-Concept. $\mathrm{SoDe}=$ Social Desirability. $\mathrm{IAT}=$ Implicit Association Test.

$* p<.05, * * p<.01$

\subsubsection{The implicit self-concept and prosocial behavior.}

We investigated the relation of the implicit MSC with prosocial behavior (H4). We had to exclude 25 children from the analysis, whose IAT performance was at chance level (see above). We calculated three multiple regressions (one for each prosocial behavior) with age and the difference score of the IAT as predictors. None of the regressions became significant with the exception of the comforting regression. Age predicted comforting behavior, $F(1,105)=5.441$, $p=.022$. Thus, the implicit MSC did not relate to prosocial behavior. 


\section{MORAL SELF-CONCEPT AND PROSOCIAL BEHAVIOR}

\subsection{Discussion}

As hypothesized, the MSC appears to be distinct from other self-concept domains (H1), to be threefold (H2), and to relate to prosocial behaviors (H3). In particular, it relates to sharing and comforting, but not to helping behavior. Contrary to our hypothesis, the implicit MSC does not relate to prosocial behaviors. We will discuss this result in the general discussion.

The MSC appears to fit in the hierarchical model(Shavelson et al., 1976):It seems to be distinct from other domains (e.g., physical and verbal; as the analyses for H1 show), that means, moral attributes are organized in a distinct category. Furthermore, the MSC appears to be threefold (helping, sharing, comforting; as the analyses of $\mathrm{H} 2$ show), or multidimensional (Marsh, Ellis, et al., 2002).Note that items representing both preferences("I like to ...") and behaviors ("I do...") appear to fit in the same dimension. This hints at a broader understanding of the dimensions. The dimensions helping, sharing, and comforting seem to be subcategories of the MSC, since the first EFA revealed a homogenous factor for the MSC.

In addition, the MSC domains appear to relate to the assessed prosocial behaviors. This finding is in line with self-perception theory (Bem, 1972). That means, prosocial behavior and MSC relate to each other meaningfully. Hence, our results relate to proposals that suggest a bridging role of the MSC between moral judgment and behavior (Hardy \& Carlo, 2011). Neither the other self-concept measures (physical and verbal) nor social desirability related to prosocial behavior. We will discuss this point further in the general discussion.

Because other studies reported ceiling effects for helping behavior in the preschool period (Engelmann, Herrmann, \& Tomasello, 2012; Svetlova et al., 2010), we decided to rely on a costly helping task. This is also morally more relevant as it requires to balance own interests and other's well-being. As a consequence, children showed less helping behavior. Please consider that the helping task was a game that the experimenter and the child played next to 


\section{MORAL SELF-CONCEPT AND PROSOCIAL BEHAVIOR}

each other rather than together. The helping task contains a conflict of interest: selfishly winning or prosocially helping. This is also true for the sharing task. As the attractive stickers belong to the child, participants have to decide if they selfishly want to keep them all, or if they prosocially want to share them with a stranger. This way helping and sharing resemble similar conflicts. Yet, it is sharing and comforting, not helping that relate to the MSC. This suggests that the presence or absence of a conflict of interest does not determine relations between the behaviors and the MSC. We will argue in the general discussion that helping behavior might have a higher social rather than prosocial focus.

One of the main findings, as this has not been investigated in previous studies, is that the MSC appears to be threefold as shown by an exploratory factor analysis. In a next step, we wanted to confirm the structure of the MSC with a second study.

\section{Study 2}

Testing the identified structure of the MSC with a new, large sample allows for a robust confirmation of the MSC dimensions. Hence, we analyzed data from different assessments that included the moral items of our puppet-interview. The sample consists of participants from different assessments that all contained the same shortened version of the puppet-interview used in study 1 (resulting from the EFA of study 1). A data set of 172 children was taken from \#\#Reference removed for blinded review\#\#. The remaining data $(\mathrm{n}=144)$ was taken from unpublished studies, which had different research questions than the present one. We expected the MSC to show the three MSC dimensions helping, sharing and comforting, that we found in the first study. In order to investigate this hypothesis, we conducted a confirmatory factor analysis (CFA) to test how well the data fit the predefined model.

\subsection{Methods}

\subsubsection{Participants}




\section{MORAL SELF-CONCEPT AND PROSOCIAL BEHAVIOR}

The sample contained 314 four- to eight-year-olds (158 female, $M=81.57$ months, $S D=$ 16.45). Children were drawn from the same population as the first sample, but were different to the first sample. We contacted parents either through data apprehended by the city's natal register or in local Kindergartens. According to a power analysis, a minimum sample of 296 participants would suffice to detect a small effect $\left(f^{2}=0.15\right)$ with a power of $80 \%$ and alpha of .05 when conducting a CFA with three factors and nine observed items. Testings took place in the lab $(n=145)$ or in Kindergartens $(n=169)$.

\subsubsection{Procedure}

The procedure of the puppet-interview was identical as in study 1 . We included the moral items that resulted as relevant by the previous EFA (Sh1, Sh3; Sh4, Co2-4, He2-4, see Table 4). Additionally, we included four distractor items (from the physical and verbal domain, 2 each), which have shown to be unrelated to the moral items. The order of the moral items differed between the subsamples of study 2 , ensuring that order of items did not influence the responses. Before the puppet-interview, all children participated in a sharing task as in study 1. Tasks after the puppet-interview differed between the subsamples. Neither the sharing task nor the subsequent tasks are part of the current research question; hence, we will not discuss them further.

\subsection{Results}

Table 6 depicts Pearson-correlations of the three summary scores of the MSC dimensions. We conducted a CFA with the items that fit the model of the first study (see H2). We set the items that should represent the MSC of sharing (Sh1, Sh3, and Sh4) as the first factor, of comforting (Co2-4) as a second factor, and of helping (He2-4) as the third factor. We used the R lavaan package(Rosseel, 2012) for computing the CFA. According to Byrne (2013), cut offs for a good model fit are CFI $>.95$, SRMR $<.05$, RMSEA $<.05$, for the Chi-squared test $>.05$. In 


\section{MORAL SELF-CONCEPT AND PROSOCIAL BEHAVIOR}

order to investigate the goodness of fit, we compared the three-factor model with a one-factor model. As the one-factor model has fewer restrictions, it should fit better than the three- factor model, if the null hypothesis (i.e., all items belong in one factor) were true. We compared the models in a $\chi^{2}$-test. Table 7 depicts results for a single-factor solution in contrast to a threefactor solution. The $\chi^{2}$-test reveals a significant difference between the two models; $\chi^{2}(9,314)=$ $77.49 ; p<.001$, in direction of a better three-factor fit (see smaller AIC-scores). Factor loadings are reported in Table 8.

Table 6

Pearson-Correlations with pair wise-deletion of MSC Domains in Study 2

\begin{tabular}{lcc}
\hline & Sharing & Comforting \\
\hline Sharing & -- & \\
Comforting & $0.42^{* * *}$ & -- \\
Helping & $0.26^{* * *}$ & $0.25^{* * *}$ \\
\hline$* * p<.01, * * * \mathrm{p}<.001$ &
\end{tabular}

Table 7

Goodness-of-Fit Indicators of Models for MSC Measure including $(n=314)$ and excluding older participants $(n=221)$

\begin{tabular}{ccccccccc}
\hline Model & $\chi^{2}$ & $\mathbf{d f}$ & $\mathbf{p}$ & $\mathbf{C F I}$ & RMSEA & SRMR & AIC & BIC \\
\hline Single Factor & 135.15 & 29 & $<.001$ & .72 & .11 & .08 & 9074.4 & 9175.5 \\
Three Factors & 34.26 & 24 & .080 & .97 & .03 & .04 & 8983.3 & 9075.5 \\
\hline \multicolumn{2}{l}{ Younger Children (4-6 years) } & & & & & & \\
Single Factor & 79.00 & 27 & $<.001$ & .79 & .09 & .07 & 6514.3 & 6605.8 \\
Three Factors & 32.26 & 24 & .121 & .97 & .04 & .04 & 6473.6 & 6575.3 \\
\hline
\end{tabular}

Comparison of Confirmatory Factor Analysis for MSC of single Factor solution vs. three Factor solution. 
MORAL SELF-CONCEPT AND PROSOCIAL BEHAVIOR

Table 8

Factor Loadings for Confirmatory Factor Analysis of the Puppet-Interview's Prosocial Items

\begin{tabular}{|c|c|c|c|}
\hline Code & Helping & Comforting & Sharing \\
\hline Sh1 & & & .58 \\
\hline $\operatorname{Sh} 3$ & & & .47 \\
\hline $\mathrm{Sh} 4$ & & & .55 \\
\hline $\mathrm{Co} 2$ & & .56 & \\
\hline $\mathrm{Co} 3$ & & .44 & \\
\hline $\mathrm{Co} 4$ & & .75 & \\
\hline $\mathrm{He} 2$ & .66 & & \\
\hline $\mathrm{He} 3$ & .60 & & \\
\hline $\mathrm{He} 4$ & .61 & & \\
\hline Cronbach's $\alpha$ & .66 & .59 & .55 \\
\hline
\end{tabular}

Note. Cronbach's $\alpha$ as measure of internal consistency

To confirm that the model fit was not driven by the higher age of the second sample, we excluded all children above six years, as our first sample only included four- to six-year-olds. We repeated the analysis with this smaller sample. With the smaller sample $(N=221$, mean age in months $=71.91, \mathrm{SD}=7.00)$, the $\chi^{2}$-testlikewise revealed a better fit of the three-factor model $\chi^{2}(9,221)=45.95, p<.001$ (see Table 7 lower part).

\subsection{Discussion}




\section{MORAL SELF-CONCEPT AND PROSOCIAL BEHAVIOR}

As hypothesized, results from the second study replicated the threefold dimensions of the MSC. A confirmatory factor analysis, ran on a large sample, revealed that the MSC of five- to eight-year-olds consists of the dimensions of helping, sharing, and comforting. This finding further strengthens the result of study 1 by showing that the MSC appears to be multidimensional as suggested by hierarchical models of the self-concept(Marsh, Ellis, et al., 2002; Shavelson et al., 1976).

\section{General Discussion}

The moral self-concept (MSC) has been suggested to play an important role in human moral development (Blasi, 1983; Hardy \& Carlo, 2011). Yet, little is known about its early development. In the current studies, we investigated whether preschoolers' MSC has an internal structure and whether it meaningfully relates to prosocial behavior. In a first study, we assessed children's explicit and implicit MSC. Moreover, we assessed prosocial behavior in terms of helping, sharing, and comforting. We expected the children to have distinct dimensions of the moral self (H1 and $\mathrm{H} 2)$ and that these explicit dimensions (H3) correspond to the according behavior. Moreover, we explored the relation between the implicit self-concept and prosocial behaviors (H4). We analyzed $\mathrm{H} 1$ and $\mathrm{H} 2$ with exploratory factor analysis. Our analysis confirmed that the MSC was distinct from other self-concept domains. More important, we found that preschoolers' MSC internally differentiated into helping, sharing, and comforting, indicating that children have a representation of themselves that differs in relation to the three different prosocial behaviors. In a second study, we replicated this factor structure. We conducted a confirmatory factor analysis with an independent, large sample indicating strong evidence for a threefold model. The dimensions of the MSC seem to be independent of age, as they appear from Kindergarten to school age. Finally, a regression analysis revealed that 


\section{MORAL SELF-CONCEPT AND PROSOCIAL BEHAVIOR}

preschoolers' explicit MSC related to the prosocial behaviors sharing and comforting. The results are in line with self-perception theory and the hierarchical structure model according to which the self-concept relates to actual behavior. Overall, our findings demonstrate that a differentiated MSC emerges in the preschool years.

Our results show that the MSC of four- to six-year-old children is distinct from two other self-concept domains, that is those from the Marsh, Ellis, et al. (2002) questionnaire. This means that children mentally represent their prosociality from early on. Our results are in line with other studies demonstrating that a differentiated view of oneself emerges in early childhood(Brown, Mangelsdorf, Agathen, \& Ho, 2008; Brunner et al., 2010). Furthermore, our data support a multifaceted model of the self-concept. The similarity between the multifaceted model of the self-concept in general and the multifaceted structure of the MSC hints to further questions. For example, the development of the academic self-concept begins with a positivity bias and, around the third grade, becomes more attuned to external indicators (Marsh \& Martin, 2011).It would be an interesting topic for future research to examine whether the MSC shows a similar developmental trajectory. Hereby, self-perception and parental feedback might be major contributors to the development of a self-concept(Bryan et al., 2014; Foster-Hanson, Cimpian, Leshin, \& Rhodes, 2018).

Importantly, we found that preschool children's MSC is internally structured. Specifically, our analyses confirmed that preschoolers possess three dimensions of MSC, which are equivalent to the prosocial behaviors described by recent theoretical frameworks (Dunfield, 2014; Paulus, 2018). Some authors suggest further prosocial domains, such as cooperation (Malti et al., 2016; Tomasello \& Vaish, 2013). We leave it up to future research to investigate further dimensions of the MSC. In line with findings of the existence of three unrelated dimensions of prosocial behaviors(Dunfield \& Kuhlmeier, 2013), the three MSC dimensions are distinct from each other. We were able to support this conclusion with an exploratory factor 


\section{MORAL SELF-CONCEPT AND PROSOCIAL BEHAVIOR}

analysis and a confirmatory factor analysis in two separate samples. Replicating the findings of study 1 with a separate sample shows how stable the distinction in helping, sharing, and comforting appears to be across samples. The current study extends previous findings that suggest two dimensions of children's MSC: avoidance of antisocial behavior and preference for prosocial behavior (see Krettenauer et al., 2013). The three factors we identified might be dimensions within preference for prosocial behavior. Helping, sharing, and comforting all represent active prosocial actions in contrast to avoidance of antisocial behavior (e.g., not hurting someone).- Previous research has mainly focused on the dimensions of the academic self-concept(Arens et al., 2016; Bossaert, Doumen, Buyse, \& Verschueren, 2011; Marsh \& Martin, 2011).Our findings extend research on preschool children's self-concept with a moral domain.

Central findings are the meaningful relations between the different MSC dimensions and the corresponding dimensions of prosocial behaviors. This is in line with self-perception theory (Bem, 1972). It suggests that preschool children register and reflect on their own prosociality. Importantly, none of the other self-concept domains predicted any of the three prosocial behaviors. That highlights the meaningful relation of children's MSC and own behavior. Although this was true for sharing and comforting behavior, it was different for helping. We will discuss the potentially special role of helping later on.

Both comforting self-concept and age predicted comforting behavior. Increasing comforting with age is in line with the literature (Kienbaum, 2014) and can be explained by developing cognitive processes: With increasing age, children recognize needs easier and gain a broader repertoire of comforting behaviors. Furthermore, moral reasoning (Malti \& Latzko, 2010) as well as empathy (Catherine \& Schonert-Reichl, 2011) improve with age, which in turn is related to increasing comforting skills (Catherine \& Schonert-Reichl, 2011). 


\section{MORAL SELF-CONCEPT AND PROSOCIAL BEHAVIOR}

Sharing and comforting self-concept predicted sharing behavior. That is, children with a stronger sharing self-concept and a stronger comforting self-concept shared more. Sharing behavior might result from different motivations: on the one hand, from a cognitive point of view, one might share in order to respect fairness norms (McAuliffe, Blake, Steinbeis, \& Warneken, 2017) and to demonstrate equal respect (Engelmann \& Tomasello, 2019); on the other hand, from a more emotional perspective, one might share out of empathy with a potential receiver who does not have any resources. Thus, one might speculate that children with a strong sharing self-concept have a stronger motivation to share in order to follow fairness norms(Paulus, Nöth, \& Wörle, 2018). On the other hand, children with a strong comforting self-concept might have a stronger motivation to share in order to reduce emotional distress (cf. Ongley \& Malti, 2014). This way, the fairness norm and the reaction to emotional distress might both motivate sharing behavior. Yet, these two motives might be related in ontogeny as the fairness norm might develop out of the caring about others' perspectives (Carpendale, 2009). That means, while these two motives may be closely intertwined in their ontogeny, they can constitute distinct motives for actual prosocial behavior.

Although we found an independent helping self-concept, it did not predict helping behavior. Instead, the helping self-concept was the only dimension that correlated with social desirability. This points to a difference in the helping compared to sharing and comforting MSC. With regard to helping behavior, there is indeed a debate on its underlying function and motivation (e.g., Carpendale, Kettner, \& Audet, 2015).For instance, Pletti, Scheel, and Paulus (2017) argue that in early childhood helping results from a generally social, rather than prosocial, motivation: children help because they want to engage in cooperative activities with other people. They might use instrumental helping (such as handing over of objects) as an opportunity to interact with others (Dahl, 2019). It is possible that in our study, helping behavior was rather triggered by children's wish to cooperatively interact with the other person (as the game they were 


\section{MORAL SELF-CONCEPT AND PROSOCIAL BEHAVIOR}

involved in was competitive, not cooperative) than by a motive to support a needy other. Recent work showed that helping based on need develops in the preschool years (Paulus, 2020).

An alternative explanation for the null-effect regarding helping might base on the especially social desirable nature of helping. Furthermore, the items to assess the helping self-concept referred to actions that relate more to adult-child interaction, whereas sharing and comforting self-concept items referred to peer interaction. In a hierarchical dyad (adult-child), adult's requests might activate child compliance. In particular, situational compliance is a reaction to requests, lacking internal motivation (Kochanska, 2002). Thus, helping could have been triggered by a motivation to comply with others rather than by prosocial motives. Further research is needed to investigate the emergence of the helping self-concept within the MSC.

Notably, we did not find a relation between the implicit MSC and prosocial behavior. Other studies reported a relation of other implicit concepts (such as attitudes) and external measures in four-year-olds (Cvencek et al., 2011).Yet, it is possible that the implicit MSC differs from other implicit concepts with respect to some properties. Implicit associations in the moral domain might take many experiences and time to build. This could explain why an implicit MSC is present in adults (Perugini \& Leone, 2009), but not in young children. It would be interesting to explore the implicit measure of a MSC across a wider age range to identify the developmental stage in which an implicit self-concept forms.

While the current study extends our knowledge on preschool children's MSC, one should note a number of limitations and open questions. One limitation concerns our "WEIRD" sample (western, educated, industrialized, rich, democratic; Henrich, Heine, \& Norenzayan, 2010). Mostly educated families replied to our invites. Research shows that socio-economic status might influence the extent of prosocial behavior. Some find that SES relates positively to prosocial behavior (Kosse, Deckers, Pinger, Schildberg-Hörisch, \& Armin, 2018), others find 


\section{MORAL SELF-CONCEPT AND PROSOCIAL BEHAVIOR}

negative relations (Piff, Kraus, Côté, Cheng, \& Keltner, 2010; Piff \& Robinson, 2017). Thus, future research with more diverse samples is warranted. Second, we did not control for task order, thus carry-over effects are possible. Further research with counter-balanced tasks is necessary. Third, the items of the current puppet-interview refer to specific actions and situations. Using this approach, we might have assessed children's preference for specific actions rather than their general view of themselves. Yet, due to the young age of the children it is necessary to use specific, everyday items (Harter, 2006), as inferring abstract concepts on behavior is just developing in preschool years (Ruble et al., 1988). We leave it to future research to explore these issues in more detail.

Despite these open questions, the current findings extend our knowledge on the emergence of the MSC. The findings suggest the existence of an internally structured MSC that shows meaningful relations to children's own sharing and comforting behavior. This enables an interesting perspective on how to foster moral development. For example, interventions on the self-concept can increase prosocial behavior in children (Bryan et al., 2014; Grusec \& Redler, 1980). One could speculate that specific attributions to the distinct self-concept dimensions might foster related behaviors systematically. Thus, this study can be groundwork for future prosocial interventions on a personal level. This is particularly important since interventions on the personal level should have a longer and stronger impact than interventions on behavioral levels (Bryan, Adams, \& Monin, 2013).

The current study demonstrated that preschoolers' self-concepts are differentiated.

Additionally, we found a relation between the dimensions of the MSC and the corresponding prosocial behaviors. This study shows the significance of the MSC in early childhood. 


\section{MORAL SELF-CONCEPT AND PROSOCIAL BEHAVIOR}

\section{References}

Allen, J. W., \& Bickhard, M. H. (2018). Stage fright: Internal reflection as a domain general enabling constraint on the emergence of explicit thought. Cognitive Development, 45, 77-91. doi: https://doi.org/10.1016/j.cogdev.2017.12.005.

Aquino, K., Freeman, D., Reed, A., Lim, V. K., \& Felps, W. (2009). Testing a social-cognitive model of moral behavior: The interactive influence of situations and moral identity centrality. Journal of Personality and Social Psychology, 97(1), 123-141. doi: 10.1037/a0015406

Aquino, K., \& Reed, A. (2002). The self-importance of moral identity. Journal of Personality and Social Psychology, 83(6), 1423-1440. doi: 10.1037/0022-3514.83.6.1423

Arens, A. K., Marsh, H. W., Craven, R. G., Yeung, A. S., Randhawa, E., \& Hasselhorn, M. (2016). Math self-concept in preschool children: Structure, achievement relations, and generalizability across gender. Early Childhood Research Quarterly, 36, 391-403. doi: 10.1016/j.ecresq.2015.12.024

Bem, D. J. (1972). Self-perception theory. In D. J. Bem (Ed.), Advances in Experimental Social Psychology (Vol. 6, pp. 1-62). New York: Academic Press.

Bender, J., O'Connor, A. M., \& Evans, A. D. (2018). Mirror, mirror on the wall: Increasing young children's honesty through inducing self-awareness. Journal of Experimental Child Psychology, 167, 414-422. doi: 10.1016/j.jecp.2017.12.001

Blasi, A. (1983). Moral cognition and moral action: A theoretical perspective. Developmental Review, 3(2), 178-210. doi: 10.1016/0273-2297(83)90029-1

Bossaert, G., Doumen, S., Buyse, E., \& Verschueren, K. (2011). Predicting children's academic achievement after the transition to first grade: A two-year longitudinal study. Journal of Applied Developmental Psychology, 32(2), 47-57. doi: 10.1016/j.appdev.2010.12.002

Brown, G. L., Mangelsdorf, S. C., Agathen, J. M., \& Ho, M. H. (2008). Young children's psychological selves: Convergence with maternal reports of child personality. Social Development, 17(1), 161-182. doi: 10.1111/j.1467-9507.2007.00421 


\section{MORAL SELF-CONCEPT AND PROSOCIAL BEHAVIOR}

Brunner, M., Keller, U., Dierendonck, C., Reichert, M., Ugen, S., Fischbach, A., \& Martin, R. (2010). The structure of academic self-concepts revisited: The nested Marsh/Shavelson model. Journal of Educational Psychology, 102(4), 964-981. doi: 10.1037/a0019644

Bryan, C. J., Adams, G. S., \& Monin, B. (2013). When cheating would make you a cheater: Implicating the self prevents unethical behavior. Journal of Experimental Psychology: General, 142(4), 1001-1005. doi: 10.1037/a0030655

Bryan, C. J., Master, A., \& Walton, G. M. (2014). "Helping” versus "being a helper”: Invoking the self to increase helping in young children. Child Development, 85(5), 1836-1842. doi: $10.1111 /$ cdev. 12244

Byrne, B. M. (2013). Structural Equation Modeling with Mplus: Basic Concepts, Applications, and Programming. New York: Routledge.

Carpendale, J. I. M. (2009). Piaget's Theory of Moral Development. In U. Müller, J. I. M. Carpendale \& L. Smith (Eds.), The Cambridge Companion to Piaget (pp. 270-286). Camebridge University Press.

Carpendale, J. I. M., Kettner, V. A., \& Audet, K. N. (2015). On the nature of toddlers' helping: Helping or interest in others' activity? Social Development, 24(2), 357-366. doi: $10.1111 /$ sode. 12094

Catherine, N. L. A., \& Schonert-Reichl, K. A. (2011). Children's perceptions and comforting strategies to infant crying: Relations to age, sex, and empathy-related responding. British Journal of Developmental Psychology, 29(3), 524-551. doi: 10.1348/026151010X521475

Christner, N., Pletti, C., \& Paulus, M. (2020). Emotion understanding and the moral self-concept as motivators of prosocial behavior in middle childhood. Cognitive Development, 55, 100893.

Cimpian, A., Hammond, M. D., Mazza, G., \& Corry, G. (2017). Young Children's Self-Concepts Include Representations of Abstract Traits and the Global Self. Child Development, 88(6), 1786-1798. doi: 10.1111/cdev.12925

Cvencek, D., Greenwald, A. G., \& Meltzoff, A. N. (2011). Measuring implicit attitudes of 4-year-olds: The preschool implicit association test. Journal of Experimental Child Psychology, 109(2), 187-200. doi: 10.1016/j.jecp.2010.11.002 


\section{MORAL SELF-CONCEPT AND PROSOCIAL BEHAVIOR}

Dahl, A. (2019). The science of early moral development: On defining, constructing, and studying morality from birth. Advances in Child Development and Behavior, 56, 1-24.

De Cuyper, K., De Houwer, J., Vansteelandt, K., Perugini, M., Pieters, G., Claes, L., \& Hermans, D. (2017). Using indirect measurement tasks to assess the self-concept of personality: A systematic review and meta-analyses. European Journal of Personality, 31(1), 8-41. doi: 10.1002/per.2092

Dunfield, K. (2014). A construct divided: prosocial behavior as helping, sharing, and comforting subtypes. Frontiers in Psychology, 5(958), 1-13. doi: 10.3389/fpsyg.2014.00958

Dunfield, K., \& Kuhlmeier, V. A. (2013). Classifying prosocial behavior: Children's responses to instrumental need, emotional distress, and material desire. Child Development, 84(5), 17661776. doi: $10.1111 / \mathrm{cdev} .12075$

Dunfield, K., Kuhlmeier, V. A., O’Connell, L., \& Kelley, E. (2011). Examining the diversity of prosocial behavior: Helping, sharing, and comforting in infancy. Infancy, 16(3), 227-247. doi: 10.1111/j.1532-7078.2010.00041.x

Eisenberg, N., Fabes, R. A., \& Spinrad, T. L. (2006). Prosocial development. In N. Eisenberg, W. Damon \& R. M. Lerner (Eds.), Handbook of Child Psychology (6 ed., Vol. 3, pp. 646-718). Hoboken, NJ: Wiley.

Engelmann, J. M., Herrmann, E., \& Tomasello, M. (2012). Five-year olds, but not chimpanzees, attempt to manage their reputations. PLoS ONE, 7(10), e48433.

Engelmann, J. M., \& Tomasello, M. (2019). Children's sense of fairness as equal respect. Trends in Cognitive Sciences, 23(6), 454-463.

Field, A. (2015). Discovering Statistics Using SPSS (4th ed.). London: Sage.

Foster-Hanson, E., Cimpian, A., Leshin, R., \& Rhodes, M. (2018). Asking children to" be helpers" backfires after setbacks. Child Development, 91(1), 1-13. doi: https://doi.org/10.1111/cdev.13147

Gerstenberg, F., Imhoff, R., Banse, R., \& Schmitt, M. (2014). Discrepancies between implicit and explicit self-concepts of intelligence: Relations to modesty, narcissism, and achievement motivation. Frontiers in Psychology, 5(85). doi: 10.3389/fpsyg.2014.00085 


\section{MORAL SELF-CONCEPT AND PROSOCIAL BEHAVIOR}

Gneezy, A., Imas, A., Brown, A., Nelson, L. D., \& Norton, M. I. (2012). Paying to be nice: Consistency and costly prosocial behavior. Management Science, 58(1), 179-187. doi: $10.1287 / \mathrm{mnsc} .1110 .1437$

Gnepp, J., \& Chilamkurti, C. (1988). Children's use of personality attributions to predict other people's emotional and behavioral reactions. Child Development, 59(3), 743-754. doi: $10.2307 / 1130573$

Greenwald, A. G., McGhee, D. E., \& Schwartz, J. L. (1998). Measuring individual differences in implicit cognition: the implicit association test. Journal of Personality and Social Psychology, 74(6), 1464.

Greenwald, A. G., Nosek, B. A., \& Banaji, M. R. (2003). Understanding and using the implicit association test: I. An improved scoring algorithm. Journal of Personality and Social Psychology, 85(2), 197-216. doi: 10.1037/0022-3514.85.2.197

Grusec, J. E., \& Redler, E. (1980). Attribution, reinforcement, and altruism: A developmental analysis. Developmental Psychology, 16(5), 525-534. doi: 10.1037/0012-1649.16.5.525

Guay, F., Marsh, H. W., \& Boivin, M. (2003). Academic self-concept and academic achievement: Developmental perspectives on their causal ordering. Journal of Educational Psychology, 95(1), 124-136.

Hardy, S., \& Carlo, G. (2011). Moral identity: What is it, how does it develop, and is it linked to moral action? Child Development Perspectives, 5(3), 212-218. doi: 10.1111/j.1750-8606.2011.00189

Harter, S. (2006). The self. In D. William (Ed.), Handbook of Child Psychology. New York: Wiley.

Harter, S. (2015). The construction of the self: Developmental and sociocultural foundations: Guilford Publications.

Henrich, J., Heine, S. J., \& Norenzayan, A. (2010). The weirdest people in the world? Behavioral and Brain Sciences, 33(2-3), 61-83. doi: 10.1017/S0140525X0999152X

Hertz, S. G., \& Krettenauer, T. (2016). Does Moral Identity Effectively Predict Moral Behavior?: A Meta-Analysis. Review of General Psychology, 20(2), 129-140. doi: 10.1037/gpr0000062

Hofmann, W., Wisneski, D. C., Brandt, M. J., \& Skitka, L. J. (2014). Morality in everyday life. Science, 345(6202), 1340-1343. 


\section{MORAL SELF-CONCEPT AND PROSOCIAL BEHAVIOR}

Imuta, K., Henry, J. D., Slaughter, V., Selcuk, B., \& Ruffman, T. (2016). Theory of mind and prosocial behavior in childhood: A meta-analytic review. Developmental Psychology, 52(8), 1192-1205. doi: 10.1037/dev0000140

Jennings, P. L., Mitchell, M. S., \& Hannah, S. T. (2015). The moral self: A review and integration of the literature. Journal of Organizational Behavior, 36(S1).

Jia, R., Lang, S. N., \& Schoppe-Sullivan, S. J. (2016). A developmental examination of the psychometric properties and predictive utility of a revised psychological self-concept measure for preschool-age children. Psychological Assessment, 28(2), 226-238. doi: 10.1037/a0039403

Kenward, B., Hellmer, K., Winter, L. S., \& Eriksson, M. (2015). Four-year-olds' strategic allocation of resources: Attempts to elicit reciprocation correlate negatively with spontaneous helping. Cognition, 136, 1-8. doi: 10.1016/j.cognition.2014.11.035

Kienbaum, J. (2014). The development of sympathy from 5 to 7 years: Increase, decline, or stability? A longitudinal study. Frontiers in Psychology, 5(468). doi: 10.3389/fpsyg.2014.00468

Knowles, A.-M., Niven, A. G., Fawkner, S. G., \& Henretty, J. M. (2009). A longitudinal examination of the influence of maturation on physical self-perceptions and the relationship with physical activity in early adolescent girls. Journal of Adolescence, 32(3), 555-566. doi: 10.1016/j.adolescence.2008.06.001

Kochanska, G. (2002). Committed compliance, moral self, and internalization: A mediational model. Developmental Psychology, 38(3), 339-351. doi: 10.1037/0012-1649.38.3.339

Kochanska, G., Koenig, J. L., Barry, R. A., Kim, S., \& Yoon, J. E. (2010). Children's conscience during toddler and preschool years, moral self, and a competent, adaptive developmental trajectory. Developmental Psychology, 46(5), 1320-1332. doi: 10.1037/a0020381

Kosse, F., Deckers, T., Pinger, P. R., Schildberg-Hörisch, H., \& Armin, F. (2018). The formation of prosociality: Causal evidence on the role of social environment. CESifo Working Paper, 1-65.

Krettenauer, T. (2013). Revisiting the moral self construct: Developmental perspectives on moral selfhood. In B. W. Sokol, F. M. Grouzet \& U. Müller (Eds.), Self-regulation and autonomy: Social and developmental dimensions of human conduct (pp. 115-140). New York: Cambridge University Press. 


\section{MORAL SELF-CONCEPT AND PROSOCIAL BEHAVIOR}

Krettenauer, T., Campbell, S., \& Hertz, S. (2013). Moral emotions and the development of the moral self in childhood. European Journal of Developmental Psychology, 10(2), 159-173. doi: $10.1080 / 17405629.2012 .762750$

Liu, D., Gelman, S. A., \& Wellman, H. M. (2007). Components of Young Children's Trait Understanding: Behavior-to-Trait Inferences and Trait-to-Behavior Predictions. Child Development, 78(5), 1543-1558. doi: 10.1111/j.1467-8624.2007.01082.x

Malti, T., \& Latzko, B. (2010). Children's moral emotions and moral cognition: Towards an integrative perspective. New Directions for Child and Adolescent Development, 2010(129), 110. doi: $10.1002 / \mathrm{cd} .272$

Malti, T., Ongley, S. F., Peplak, J., Chaparro, M. P., Buchmann, M., Zuffianò, A., \& Cui, L. (2016). Children's sympathy, guilt, and moral reasoning in helping, cooperation, and sharing: A 6-year longitudinal study. Child Development, 87(6), 1783-1795. doi: 10.1111/cdev.12632

Marsh, H. W. (1990). A multidimensional, hierarchical model of self-concept: Theoretical and empirical justification. Educational Psychology Review, 2(2), 77-172.

Marsh, H. W., Ellis, L. A., \& Craven, R. G. (2002). How do preschool children feel about themselves? Unraveling measurement and multidimensional self-concept structure. Developmental Psychology, 38(3), 376-393. doi: 10.1037//0012-1649.38.3.376

Marsh, H. W., Hau, K.-T., \& Kong, C.-K. (2002). Multilevel causal ordering of academic self-concept and achievement: Influence of language of instruction (English compared with Chinese) for Hong Kong students. American Educational Research Journal, 39(3), 727-763. doi: $10.3102 / 00028312039003727$

Marsh, H. W., \& Martin, A. J. (2011). Academic self-concept and academic achievement: Relations and causal ordering. British Journal of Educational Psychology, 81(1), 59-77. doi: $10.1348 / 000709910 \times 503501$

McAuliffe, K., Blake, P. R., Steinbeis, N., \& Warneken, F. (2017). The developmental foundations of human fairness. Nature Human Behaviour, 1(2), 1-9.

Measelle, J. R., Ablow, J. C., Cowan, P. A., \& Cowan, C. P. (1998). Assessing young children's views of their academic, social, and emotional lives: An evaluation of the self-perception scales of 


\section{MORAL SELF-CONCEPT AND PROSOCIAL BEHAVIOR}

the Berkeley Puppet Interview. Child Development, 69(6), 1556-1576. doi: 10.1111/j.14678624.1998.tb06177.x

Measelle, J. R., John, O. P., Ablow, J. C., Cowan, P. A., \& Cowan, C. P. (2005). Can children provide coherent, stable, and valid self-reports on the big five dimensions? A longitudinal study from ages 5 to 7. Journal of Personality and Social Psychology, 89(1), 90.

Mezulis, A. H., Abramson, L. Y., Hyde, J. S., \& Hankin, B. L. (2004). Is there a universal positivity bias in attributions? A meta-analytic review of individual, developmental, and cultural differences in the self-serving attributional bias. Psychological Bulletin, 130(5), 711-747.

Newton, E. K., Goodman, M., \& Thompson, R. A. (2014). Why do some toddlers help a stranger? Origins of individual differences in prosocial behavior. Infancy, 19(2), 214-226. doi: 10.1111/infa. 12043

Ongley, S. F., \& Malti, T. (2014). The role of moral emotions in the development of children's sharing behavior. Developmental Psychology, 50(4), 1148-1159. doi: 10.1037/a0035191

Paulus, M. (2018). The multidimensional nature of early prosocial behavior: a motivational perspective. Current Opinion in Psychology, 20, 111-116. doi: 10.1016/j.copsyc.2017.09.003.

Paulus, M. (2020). Is young children's helping affected by helpees' need? Preschoolers, but not infants selectively help needy others. Psychological Research, 84(5), 1440-1450.

Paulus, M., Nöth, A., \& Wörle, M. (2018). Preschoolers' resource allocations align with their normative judgments. Journal of Experimental Child Psychology, 175, 117-126. doi: 10.1016/j.jecp.2018.05.001

Perugini, M., \& Leone, L. (2009). Implicit self-concept and moral action. Journal of Research in Personality, 43(5), 747-754. doi: 10.1016/j.jrp.2009.03.015

Peters, K. R., \& Gawronski, B. (2011). Mutual influences between the implicit and explicit selfconcepts: The role of memory activation and motivated reasoning. Journal of Experimental Social Psychology, 47(2), 436-442. doi: 10.1016/j.jesp.2010.11.015

Piff, P. K., Kraus, M. W., Côté, S., Cheng, B. H., \& Keltner, D. (2010). Having less, giving more: The influence of social class on prosocial behavior. Journal of Personality and Social Psychology, 99(5), 771-784. doi: 10.1037/a0020092 


\section{MORAL SELF-CONCEPT AND PROSOCIAL BEHAVIOR}

Piff, P. K., \& Robinson, A. R. (2017). Social class and prosocial behavior: Current evidence, caveats, and questions. Current Opinion in Psychology, 18, 6-10. doi: 10.1016/j.copsyc.2017.06.003

Pletti, C., Scheel, A., \& Paulus, M. (2017). Intrinsic altruism or social motivation-what does pupil dilation tell us about children's helping behavior? Frontiers in Psychology, 8. doi: 10.3389/fpsyg.2017.02089

Reynolds, S. J., \& Ceranic, T. L. (2007). The effects of moral judgment and moral identity on moral behavior: an empirical examination of the moral individual. Journal of Applied Psychology, 92(6), 1610-1624. doi: 10.1037/0021-9010.92.6.1610

Rholes, W. S., \& Ruble, D. N. (1984). Children's understanding of dispositional characteristics of others. Child Development, 55(2), 550-560. doi: 10.2307/1129966

Robinson, J. L., Zahn-Waxler, C., \& Emde, R. N. (1994). Patterns of development in early empathic behavior: Environmental and child constitutional influences. Social Development, 3(2), 125145. doi: 10.1111/j.1467-9507.1994.tb00032.x

Rosseel, Y. (2012). Lavaan: An R package for structural equation modeling and more. Version 0.5-12 (BETA). Journal of Statistical software, 48(2), 1-36.

Ruble, D. N., Newman, L. S., Rholes, W. S., \& Altshuler, J. (1988). Children's “naÏve psychology”: The use of behavioral and situational information for the prediction of behavior. Cognitive Development, 3(1), 89-112.

Salley, C. G., Vannatta, K., Gerhardt, C. A., \& Noll, R. B. (2010). Social self-perception accuracy: Variations as a function of child age and gender. Self and Identity, 9(2), 209-223. doi: $10.1080 / 15298860902979224$

Schmidt, I., Brunner, M., Keller, L., Scherrer, V., Wollschläger, R., Baudson, T. G., \& Preckel, F. (2017). Profile formation of academic self-concept in elementary school students in grades 1 to 4. PLoS ONE, 12(5). doi: 10.1371/journal.pone.0177854

Sengsavang, S., \& Krettenauer, T. (2015). Children's Moral Self-Concept: The Role of Aggression and Parent-Child Relationships. Merrill-Palmer Quarterly, 61(2), 213-235. 


\section{MORAL SELF-CONCEPT AND PROSOCIAL BEHAVIOR}

Shavelson, R. J., Hubner, J. J., \& Stanton, G. C. (1976). Self-concept: Validation of construct interpretations. Review of Educational Research, 46(3), 407-441. doi: $10.3102 / 00346543046003407$

Smith, C. E., Blake, P. R., \& Harris, P. L. (2013). I should but I won't: Why young children endorse norms of fair sharing but do not follow them. PLoS ONE, 8(3), 1-11. doi: 10.1371/journal.pone.0059510

Stevens, J. P. (2012). Applied multivariate statistics for the social sciences. New York: Routledge.

Strack, F., \& Deutsch, R. (2004). Reflective and impulsive determinants of social behavior. Personality and Social Psychology Review, 8(3), 220-247. doi: $10.1207 / \mathrm{s} 15327957 \mathrm{pspr} 0803 \_1$

Svetlova, M., Nichols, S. R., \& Brownell, C. A. (2010). Toddlers prosocial behavior: From instrumental to empathic to altruistic helping. Child Development, 81(6), 1814-1827. doi: 10.1111/j.1467-8624.2010.01512.x

Taylor, Z. E., Eisenberg, N., Spinrad, T. L., Eggum, N. D., \& Sulik, M. J. (2013). The relations of egoresiliency and emotion socialization to the development of empathy and prosocial behavior across early childhood. Emotion, 13(5), 822-831. doi: 10.1037/a0032894

Tomasello, M. (2019). Becoming human: A theory of ontogeny. Cambridge, MA.: Belknap Press. Tomasello, M., \& Vaish, A. (2013). Origins of human cooperation and morality. Annual Review of Psychology, 64, 231-255.

Vaish, A., Carpenter, M., \& Tomasello, M. (2009). Sympathy through affective perspective taking and its relation to prosocial behavior in toddlers. Developmental Psychology, 45(2), 534.

Vaish, A., Carpenter, M., \& Tomasello, M. (2016). The early emergence of guilt-motivated prosocial behavior. Child Development, 87(6), 1772-1782.

Young, S. K., Fox, N. A., \& Zahn-Waxler, C. (1999). The relations between temperament and empathy in 2-year-olds. Developmental Psychology, 35(5), 1189-1197. doi: 10.1037/00121649.35.5.1189 
